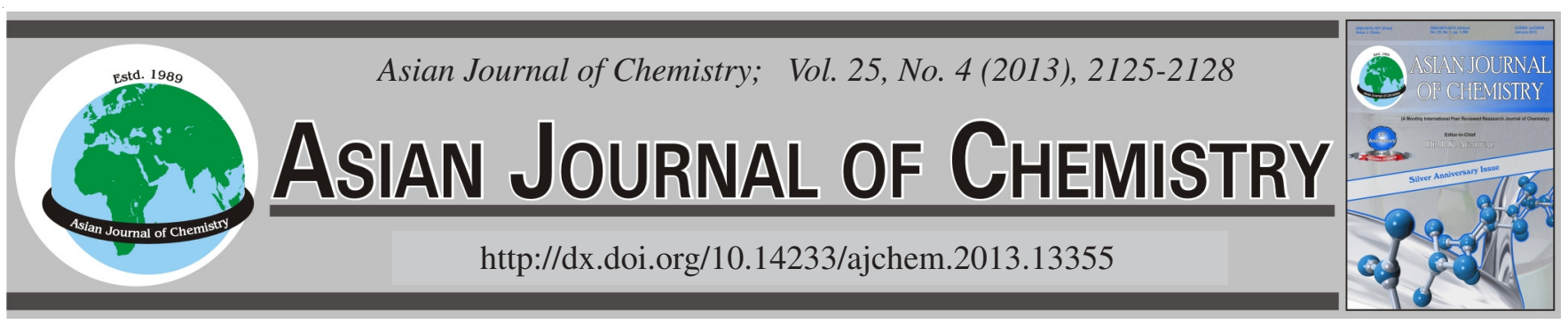

\title{
Kinetic and Thermodynamic Studies on Removal of Selenium from Aqueous Solution by Using $\mathrm{Nano}^{-\mathrm{TiO}_{2}}$
}

\author{
Ting Huang
}

Department of Chemistry and Chemical Engineering, Ankang University, Ankang, Shaanxi Province, P.R. China

Corresponding author: Fax: +86915 3261415; Tel: +86 915 3261415; E-mail: tingyu2008jh@126.com

\begin{abstract}
A novel sorbent, nano- $\mathrm{TiO}_{2}$ was employed for the removal of selenium from aqueous solution in batch equilibrium experiments, in order to investigate its adsorption properties. The removal percentage of selenium by the sorbent increased with increasing $\mathrm{pH}$ in the acidic medium. The adsorption capacities and removal percentage of $\mathrm{Se}(\mathrm{IV})$ onto nano- $\mathrm{TiO}_{2}$ were evaluated as a function of the solution concentration and temperature. The sorption of $\mathrm{Se}(\mathrm{IV})$ ions onto nano- $\mathrm{TiO}_{2}$ followed the second-order rate equation and the Langmuir model could describe the adsorption of nano- $\mathrm{TiO}_{2}$ to $\mathrm{Se}(\mathrm{IV})$ ions successfully over the whole range of concentration studied. The value of standard enthalpy and standard entropy $\left(\Delta \mathrm{H}^{\circ}, \Delta \mathrm{S}^{\circ}>0\right)$ may be interpreted as the endothermic adsorption process. The negative value of $\Delta \mathrm{G}^{\mathrm{o}}$ showed the adsorptions of $\mathrm{Se}(\mathrm{IV})$ by nano- $\mathrm{TiO}_{2}$ were a spontaneous process.
\end{abstract}

Key Words: Selenium, Nano-TiO 2 , Adsorption, Kinetics, Thermodynamics.

\section{INTRODUCTION}

Selenium is a natural trace element found in bedrock, but it is also introduced into the environment by anthropogenic activities, such as mining and combustion of fossil fuels ${ }^{1,2}$. At low concentrations, selenium is an essential micronutrient for mammals, but consumption of quantities exceeding daily recommendations can cause health problems. Its toxicity ${ }^{3}$ led the World Health Organization and the European Union to recommend a maximum selenium concentration in drinking water of $10 \mathrm{ppb}$, while the EPA sets a limit of $50 \mathrm{ppb}$.

The methods for selenium removal are membrane filtration, microbial reduction and anion exchange. Membrane filtration is expensive, due to low selectivity and fouling problems ${ }^{4-6}$. Microbial treatment, based on reduction to elementary selenium $^{7,8}$, is sensitive to oxygen and nitrate and high carbon concentrations are required ${ }^{9,10}$. Ion-exchange resins show selectivity for selenate or selenite ${ }^{5}$, but sulfate reduces removal and its precipitation with barium prior to filtration is therefore recommended $^{11}$.

The nanometer material is a new functional material, which has attracted much attention due to its special properties. Nano-material is meant clusters of atoms or molecules of metal and oxide, ranging in size from $1 \mathrm{~nm}$ to almost $100 \mathrm{~nm}$, falling between single atoms or molecules and bulk materials. Most of the atoms of nano-material is on the surface, where atoms are unsaturated and can easily bind with other atoms and possess high chemical activity. Consequently, nano-material can adsorb selectively metal ions and has a very high adsorption capacity. Besides, the operation is simple, rapid and frees from above mentioned drawbacks. So there is a growing interest in the application of nanoparticles as sorbents ${ }^{12}$. Recently it has been reported that titanium dioxide nanoparticles are used for separation and preconcentration of trace metal ions ${ }^{13,14}$. And we have successfully reported on preconcentration of thallium by nano- $\mathrm{TiO}_{2}{ }^{15}$.

In this study, titanium dioxide nanoparticles were employed for the sorption of selenium from aqueous solution. The process was studied in detail by varying the sorption time, $\mathrm{pH}$, selenium concentration, temperature and amount of sorbent. The kinetics and thermodynamics of selenium adsorption on nano- $\mathrm{TiO}_{2}$ were studied. The results show that the equilibrium time for nano- $\mathrm{TiO}_{2}$ to absorb selenium is $50 \mathrm{~s}$, the adsorption percentage is $93 \%$ and the adsorption capacity is $32165 \mu \mathrm{g} / \mathrm{g}$.

\section{EXPERIMENTAL}

A stock solution of $\mathrm{Se}(\mathrm{IV})\left(1.0000 \mathrm{mg} \mathrm{mL}^{-1}\right)$ was prepared by dissolving $1 \mathrm{~g}$ of Se $(99.99 \%$ pure, Tianjin Chemical Reagent Co., China) with $10 \mathrm{~mL}$ of concentrated nitric acid and $2 \mathrm{~mL}$ of $(3+2) \mathrm{H}_{2} \mathrm{SO}_{4}$, then evaporated until without nitric acid. After cooling to room temperature, the solution diluted to a $1 \mathrm{~L}$ volumetric flask with doubly distilled water, followed by a model PF6A-2 Non-dispersion Atomic 
Fluorescence Spectrophotometer (Beijing Purkinje General Instrument Co., China) analysis.

$\mathrm{KBH}_{4}$ and $\mathrm{HCl}(5 \%)$ were used as carrier liquid with current preparation to determine selenium by a model PF6A2 non-dispersion atomic fluorescence spectrophotometer. A solution of $\mathrm{KBH}_{4}$ was prepared by dissolving $15.0000 \mathrm{~g}$ of $\mathrm{KBH} \backslash$ with $100 \mathrm{~mL}$ of $\mathrm{KOH}(5 \%)$, finally diluted to a $1 \mathrm{~L}$ volumetric flask with doubly distilled water.

All of the reagents including $\mathrm{KBH}_{4}$, ammonia, hydrochloric acid, nitric acid and sodium hydroxide, were of analytical grade and obtained from Tianjin Chemical Reagent Co., China. Doubly distilled water was used throughout experiments. Nano- $\mathrm{TiO}_{2}$ (anatase) that was used as sorbent in this study was provided from Zhoushanmingri Nanometer Material Co. and its particle size was about 10-15 nm.

Procedure: The adsorption experiments were carried out in a series of $50 \mathrm{~mL}$ Erlenmeyer flasks containing $0.10 \mathrm{~g}$ nano$\mathrm{TiO}_{2}$ and $10 \mathrm{~mL}$ of $10 \mathrm{mg} \mathrm{L}^{-1}$ selenium solution at $\mathrm{pH} 11$. If necessary, an appropriate volume of $0.1 \mathrm{~mol} / \mathrm{L} \mathrm{HCl}$ or $\mathrm{NaOH}$ solutions was used to adjust the $\mathrm{pH}$ of the solution after addition of nano- $\mathrm{TiO}_{2}$. The soild/liquid phases were separated by centrifuging at $3000 \mathrm{rpm}$. The adsorption percentage (ads. $\%$ ) was calculated as

$$
\text { Adsorption percentage }=\frac{\left(\mathrm{C}_{\mathrm{i}}-\mathrm{C}_{\mathrm{a}}\right)}{\mathrm{C}_{\mathrm{i}}} \times 100
$$

where $C_{i}$ and $C_{a}$ are the initial and the final concentration of $\mathrm{Se}(\mathrm{IV})$ in solution phase, respectively.

The fact that $\mathrm{q}$ is the amount of $\mathrm{Se}(\mathrm{IV})$ adsorbed per unit weight of nano- $\mathrm{TiO}_{2}\left(\mu \mathrm{g} \mathrm{g}^{-1}\right)$ was calculated using the equation:

$$
\mathrm{q}=\frac{\left(\mathrm{C}_{\mathrm{i}}-\mathrm{C}_{\mathrm{a}}\right) \mathrm{v}}{\mathrm{m}}
$$

where $\mathrm{m}$ is the mass of the sorbent $(\mathrm{g}), \mathrm{v}$ is the volume of the solution $(\mathrm{mL})$.

Adsorption isotherm studies were carried out with different initial concentrations of Se(IV) while maintaining the sorbent dosage at constant level. In order to inspect any adsorption of selenium on the container surface, control experiments were carried out without the sorbent. It was found that no adsorption occurred on the container wall.

Kinetic experiments were conducted using a known weight of the sorbent dosage at the different temperatures. After regular intervals of time, suitable aliquots were analyzed for selenium concentration. The rate constants were calculated using the conventional rate expression. The thermodynamic parameters for the process of adsorption were determined at a particular temperature. This procedure was repeated at different temperatures.

\section{RESULTS AND DISCUSSION}

Effect of pH: In this study, pH is an important parameter because the $\mathrm{pH}$ of solution influences the distribution of active sites on the surface of nano- $\mathrm{TiO}_{2}$. At the lower $\mathrm{pH}$, the hydrion on the surface of nano- $\mathrm{TiO}_{2}$ provides the ability of binding anions. The increase of $\mathrm{pH}$ leads to the neutralization of surface charge and hydrion is displaced from the surface, so the adsorption of cations onto nano- $\mathrm{TiO}_{2}$ increases quickly. Fig. 1 shows the effect of $\mathrm{pH}$ on the adsorption of $\mathrm{Se}(\mathrm{IV})$ by nano- $\mathrm{TiO}_{2}$. The recovery of selenium increased with an increase in $\mathrm{pH}$. Thus, $\mathrm{pH} 11$ was chosen for the adsorption Se(IV). The adsorption percentage was calculated to be $93 \%$ at $\mathrm{pH} 11$.

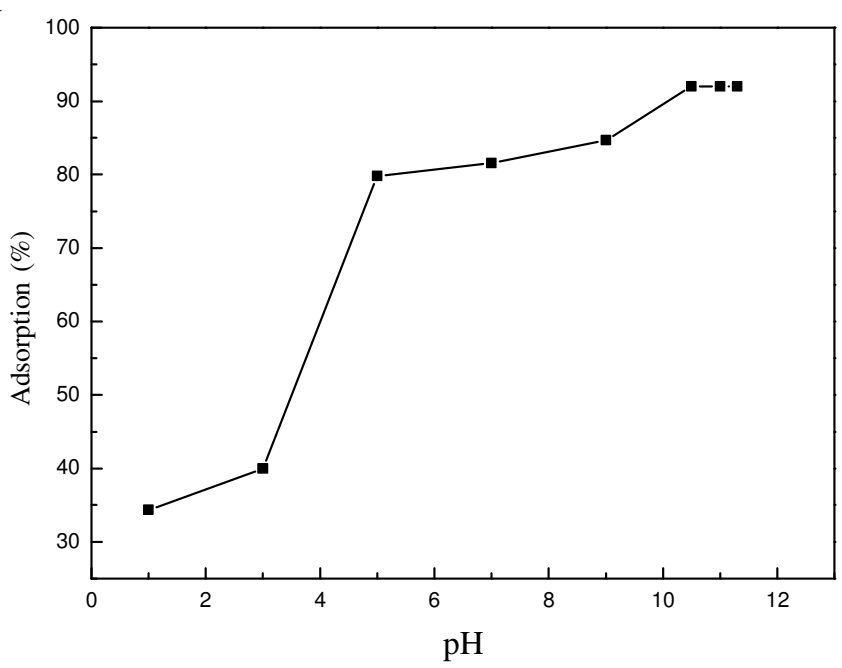

Fig. 1. Effect of $\mathrm{pH}$ on the adsorption efficiency of $\mathrm{Se}(\mathrm{IV})$ on nano- $\mathrm{TiO}_{2}$; $100 \mathrm{mg}$ of nano- $\mathrm{TiO}_{2} ; \mathrm{C}_{\mathrm{Se}(\mathrm{IV})} 10.0 \mathrm{mg} \mathrm{L}^{-1}$; static for $50 \mathrm{~s}$; temperature $20 \pm 0.1^{\circ} \mathrm{C}$

Adsorption kinetic model: The models of adsorption kinetics were correlated with the solute uptake rate; hence these models are important in water treatment process design. In this study, for a batch of reactions, the adsorption dynamics was followed by conducting the adsorption of Se(IV) on nano$\mathrm{TiO}_{2}$ at optimized $\mathrm{pH}$ and the sorbent dosage.

Experiments were performed in order to investigate the kinetics of selenium removal by nano- $\mathrm{TiO}_{2}$.

The sorption kinetics may be described by the pseudofirst-order Lagergren rate model. The equation is as follows ${ }^{16}$ :

$$
\ln \left(\mathrm{q}_{1}-\mathrm{q}_{\mathrm{t}}\right)=\ln \mathrm{q}_{1}-\mathrm{k}_{1} \mathrm{t}
$$

where $\mathrm{q}_{1}$ and $\mathrm{q}_{\mathrm{t}}$ are the amounts of $\mathrm{Se}(\mathrm{IV})$ adsorbed on the sorbent $\left(\mu \mathrm{g} \mathrm{g}^{-1}\right)$ at equilibrium and at time $\mathrm{t}$, respectively and $\mathrm{k}_{1}$ is the rate constant of the first-order adsorption $\left(\mathrm{s}^{-1}\right)$. The straight-line plots of $\ln \left(\mathrm{q}_{1}-\mathrm{q}_{\mathrm{t}}\right)$ against $\mathrm{t}$ were used to determine the rate constant, $\mathrm{k}_{1}$ and correlation coefficient, $\mathrm{r}_{1}$ values of the $\mathrm{Se}$ (IV) under different concentration range were calculated from these plots.

The Ho's pseudo-second-order model may also describe the kinetics of sorption of selenium on nano- $\mathrm{TiO}_{2}$. Thus the kinetic rate law can be rewritten as follows ${ }^{17}$ :

$$
\frac{\mathrm{t}}{\mathrm{q}_{\mathrm{t}}}=\frac{1}{\mathrm{k}_{2} \mathrm{q}_{2}^{2}}+\frac{\mathrm{t}}{\mathrm{q}_{2}}
$$

where $\mathrm{k}_{2}$ is the rate constant of second-order adsorption

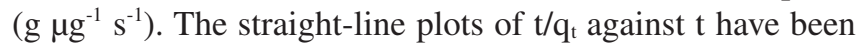
tested to obtain rate parameters and it suggests the applicability of this kinetic model to fit the experimental data.

The validity of both kinetic models is checked. The results of the kinetic parameters for Se(IV) adsorption are listed in Table-1. Based on the correlation coefficients, the adsorption of $\mathrm{Se}(\mathrm{IV})$ is best described by the pseudo-second-order equation. 


\begin{tabular}{|c|c|c|c|c|c|c|}
\hline \multicolumn{7}{|c|}{ 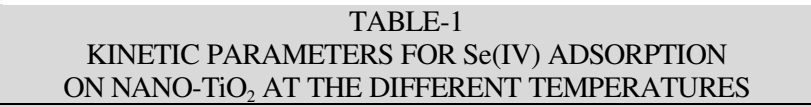 } \\
\hline $\begin{array}{c}\mathrm{T} \\
(\mathrm{K})\end{array}$ & $\mathrm{k}_{1}\left(\mathrm{~s}^{-1}\right)$ & $\begin{array}{c}\mathrm{q}_{1}(\mu \mathrm{g} \\
\left.\mathrm{g}^{-1}\right)\end{array}$ & $\mathrm{r}_{1}$ & $\mathrm{k}_{2}\left(\mathrm{~g} \mu \mathrm{g}^{-1} \mathrm{~s}^{-1}\right)$ & $\begin{array}{c}\mathrm{q}_{2}(\mu \mathrm{g} \\
\left.\mathrm{g}^{-1}\right)\end{array}$ & $\mathrm{r}_{2}$ \\
\hline 273 & 0.005458 & 427.7 & 0.850 & 0.0002671 & 450.8 & 0.999 \\
\hline 293 & 0.002971 & 520.5 & 0.884 & 0.0003927 & 467.3 & 0.999 \\
\hline 313 & 0.002107 & 511.9 & 0.862 & 0.0006057 & 471.7 & 0.999 \\
\hline
\end{tabular}

It was possible to calculate the activation energy for adsorption employing Arrhenius equation for the rate cons$\tan t^{18}$ based on the result in Table-1. Arrhenius equation is as follows:

$$
\mathrm{k}=\mathrm{A} \exp \left(-\frac{\mathrm{E}_{\mathrm{a}}}{\mathrm{RT}}\right)
$$

where $\mathrm{A}$ is the frequency factor $\left(\mathrm{min}^{-1}\right), \mathrm{E}_{\mathrm{a}}$ the activation energy $\left(\mathrm{kJ} \mathrm{mol}^{-1}\right), \mathrm{R}$ is the ideal gas constant $\left(\mathrm{J} \mathrm{mol}^{-1} \mathrm{~K}^{-1}\right), \mathrm{T}$ the absolute temperature $(\mathrm{K})$.

Eqn. 5 can be converted into eqn. 6 by taking logarithm

$$
\ln \mathrm{k}=\ln \mathrm{A}-\frac{\mathrm{E}_{\mathrm{a}}}{\mathrm{RT}}
$$

Thus, $\mathrm{E}_{\mathrm{a}}$ could be obtained from the slope of the line plotting ln k vs. 1000/T (Fig. 2) and the estimated $\mathrm{E}_{\mathrm{a}}$ for $\mathrm{Se}$ (IV) adsorption on nano- $\mathrm{TiO}_{2}$ was $14.47 \mathrm{~kJ} \mathrm{~mol}^{-1}$.

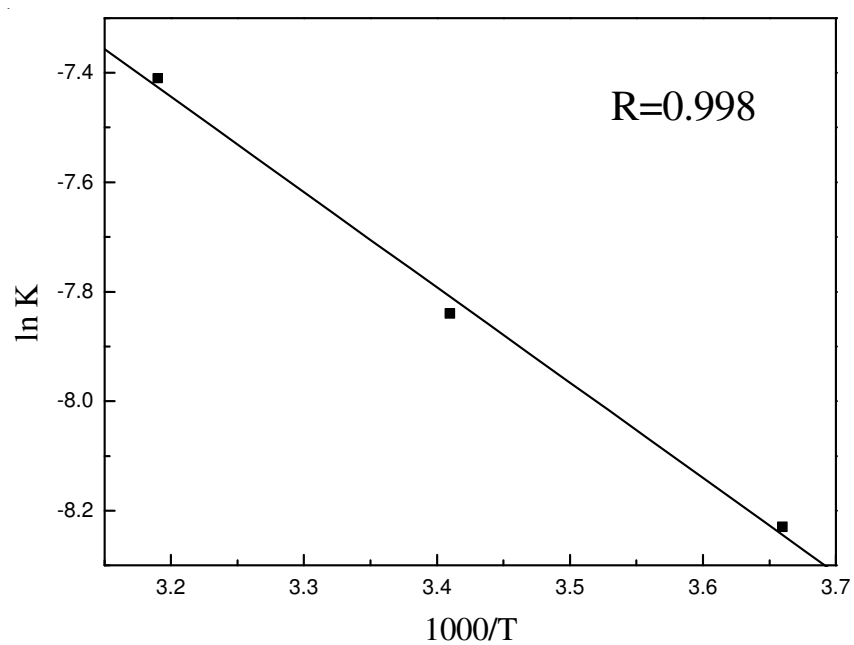

Fig. 2. Plot of $\ln \mathrm{k} v s$. 1000/T (the points correspond to $273,293,313 \mathrm{~K}$ ); $100 \mathrm{mg}$ of nano- $\mathrm{TiO}_{2} ; \mathrm{C}_{\mathrm{Se}(\mathrm{IV})} 10 \mathrm{mg} \mathrm{L} \mathrm{m}^{-1} ; \mathrm{pH} 11$

Adsorption isotherm and adsorption capacity: The equilibrium adsorption of $\mathrm{Se}(\mathrm{IV})$ on nano- $\mathrm{TiO}_{2}$ as a function of the initial concentration of $\mathrm{Se}(\mathrm{IV})$ is shown in Fig. 3. There was a gradual increase of adsorption for $\mathrm{Se}(\mathrm{IV})$ ions until the equilibrium was attained. Adsorption isotherm is important to describe how solutes interact with the sorbent. The Langmuir models are often used to describe equilibrium sorption isotherms. The most widely used Langmuir equation, which is valid for monolayer sorption on a surface with a finite number of identical sites, is given by:

$$
\frac{\mathrm{C}_{\mathrm{e}}}{\mathrm{q}_{\mathrm{e}}}=\frac{\mathrm{C}_{\mathrm{e}}}{\mathrm{q}_{\max }}+\frac{1}{\mathrm{bq}_{\max }}
$$

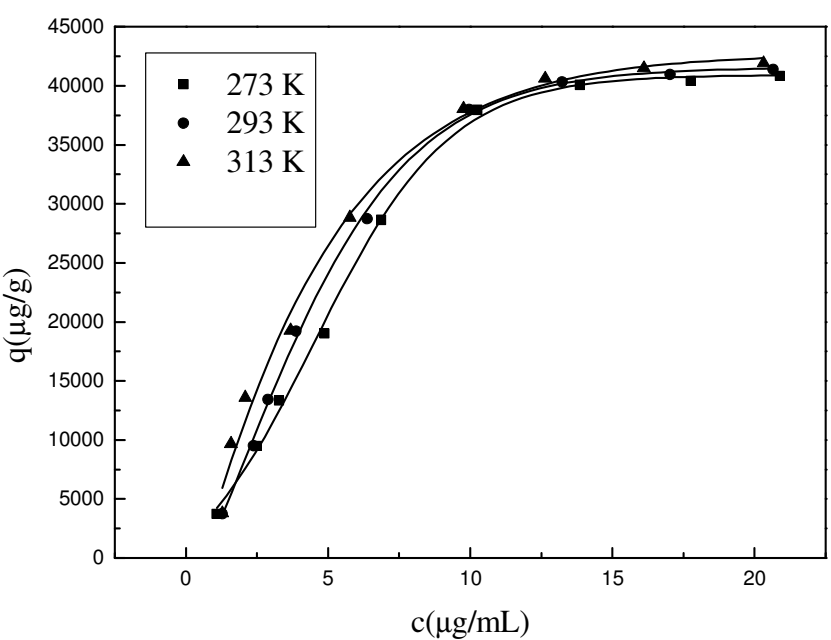

Fig. 3. Isotherm of $\mathrm{Se}(\mathrm{IV})$ adsorption on nano- $\mathrm{TiO}_{2}$ at different temperatures $(273,293,313 \mathrm{~K}) ; 100 \mathrm{mg}$ of nano- $\mathrm{TiO}_{2}$; the initial $\mathrm{Se}(\mathrm{IV})$ concentration range was $0-200.0 \mathrm{mg} \mathrm{L}^{-1}$; static for $50 \mathrm{~s}$; $\mathrm{pH}$ 11

where $\mathrm{q}_{\max }$ is the maximum adsorption at monolayer $\left(\mu \mathrm{g} \mathrm{g}^{-1}\right)$, $\mathrm{C}_{\mathrm{e}}$ is the equilibrium concentration of $\mathrm{Se}(\mathrm{IV}), \mathrm{q}_{\mathrm{e}}$ is the amount of $\mathrm{Se}(\mathrm{IV})$ adsorbed per unit weight of nano- $\mathrm{TiO}_{2}$ at equilibrium concentration $\left(\mu \mathrm{g} \mathrm{g}^{-1}\right)$ and $\mathrm{b}$ is the Langmuir constant related to the affinity of binding sites. A linearized plot of $\mathrm{C}_{\mathrm{e}} / \mathrm{q}_{\mathrm{e}}$ against $\mathrm{C}_{\mathrm{e}}$ gives $\mathrm{q}_{\max }$ and $\mathrm{b}$ (Fig. 4).

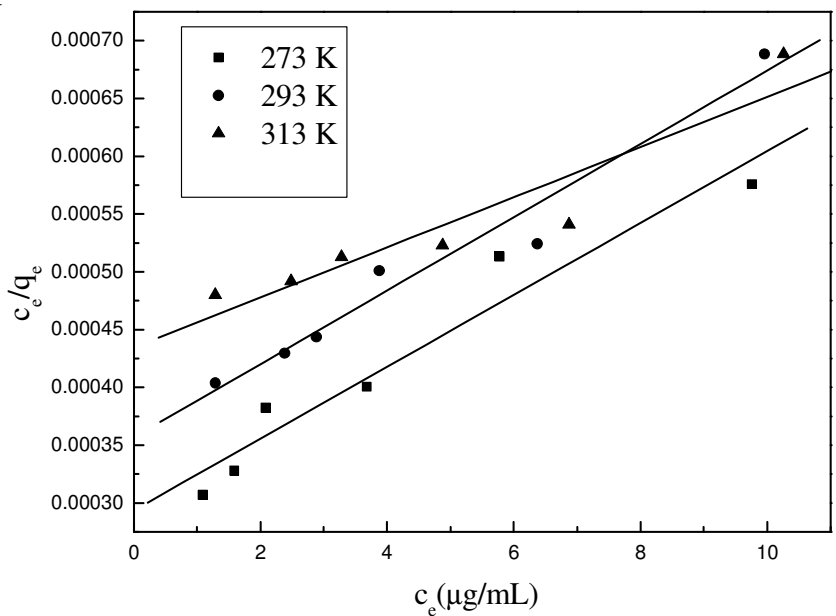

Fig. 4. Langmuir adsorption isotherm at different temperatures (273, 293, $313 \mathrm{~K}$ ); $100 \mathrm{mg}$ of nano- $\mathrm{TiO}_{2}$; the initial $\mathrm{Se}(\mathrm{IV})$ concentration range was $0-200 \mathrm{mg} \mathrm{L}^{-1}$; static for $50 \mathrm{~s} ; \mathrm{pH} 11$

The calculated results of the Langmuir isotherm constants are given in Table-2. Fig. 4 shows that the adsorption of Se(IV) on nano- $\mathrm{TiO}_{2}$ was correlated well $(\mathrm{R}>0.99)$ with the Langmuir equation. The maximum adsorption capacity of selenium ions on nano- $\mathrm{TiO}_{2}$ was 31506,32165 and $46104 \mu \mathrm{g} / \mathrm{g}$ at 0,20 and $40{ }^{\circ} \mathrm{C}$, respectively.

Thermodynamic studies: The experiments were carried out at 273,293 and $313 \mathrm{~K}$ for different concentrations, respectively. The values of $\Delta \mathrm{H}^{\circ}$ were calculated from the slopes and intercepts of linear regression of $\ln \mathrm{C}$ versus $1 / \mathrm{T}$ using the Clausius-Clapeyron equation ${ }^{19,20}$

$$
\ln \mathrm{C}=\frac{\Delta \mathrm{H}^{\mathrm{o}}}{\mathrm{RT}}+\mathrm{D}
$$




\begin{tabular}{|c|c|c|c|c|}
\hline \multicolumn{5}{|c|}{$\begin{array}{c}\text { TABLE-2 } \\
\text { LANGMUIR ISOTHERM CONSTANTS AND CORRELATION } \\
\text { COEFFICIENTS AT THE DIFFERENT TEMPERATURES }\end{array}$} \\
\hline \multirow{3}{*}{$\begin{array}{c}\mathrm{T} \\
(\mathrm{K})\end{array}$} & Langmuir equation & \multirow{3}{*}{ b } & \multirow{3}{*}{$\underset{(\mu \mathrm{g} / \mathrm{g})}{\mathrm{q}_{\mathrm{m}}}$} & \multirow{3}{*}{$\mathrm{R}$} \\
\hline & $\underline{\mathrm{C}_{\mathrm{e}}}=\frac{\mathrm{C}_{\mathrm{e}}}{+}+\frac{1}{1}$ & & & \\
\hline & $\overline{q_{\mathrm{e}}}-\overline{\mathrm{q}_{\max }}+\overline{\mathrm{bq}_{\max }}$ & & & \\
\hline 273 & $\mathrm{C} / \mathrm{q}=0.00003174 \mathrm{C}+0.0002935$ & 0.1059 & 31506 & 0.990 \\
\hline 293 & $\mathrm{C} / \mathrm{q}=0.00003109 \mathrm{C}+0.0003568$ & 0.0890 & 32165 & 0.991 \\
\hline 313 & $\mathrm{C} / \mathrm{q}=0.00002169 \mathrm{C}+0.0004344$ & 0.0500 & 46104 & 0.998 \\
\hline
\end{tabular}

where $\mathrm{C}$ is the equilibrium concentration of $\mathrm{Se}(\mathrm{IV})$ in solution $(\mathrm{mg} / \mathrm{L})$ and $\mathrm{D}$ is the intercept of the plot of $\ln \mathrm{C}$ versus 1/T. $\Delta \mathrm{H}^{\mathrm{o}}$ was assumed to be constant for a constant surface coverage.

To calculate the values of the other parameters $\left(\Delta \mathrm{G}^{\mathrm{o}}, \Delta \mathrm{S}^{\mathrm{o}}\right)$ the following equations were used:

$$
\begin{gathered}
\mathrm{K}_{\mathrm{C}}=\frac{\mathrm{C}_{\mathrm{Be}}}{\mathrm{C}_{\mathrm{Ae}}} \\
\Delta \mathrm{G}^{\mathbf{o}}=-\mathrm{RT} \ln \mathrm{K}_{\mathrm{C}} \\
\Delta \mathrm{S}^{\mathbf{o}}=\frac{\left(\Delta \mathrm{H}^{\mathbf{o}}-\Delta \mathrm{G}^{\mathbf{o}}\right)}{\mathrm{T}}
\end{gathered}
$$

where $\mathrm{C}_{\mathrm{Be}}$ and $\mathrm{C}_{\mathrm{Ae}}$ are the equilibrium concentrations of $\mathrm{Se}$ (IV) on the sorbent and solution, respectively, $\mathrm{K}_{\mathrm{C}}$ is the equilibrium constant, $\Delta \mathrm{S}^{\circ}$ is standard entropy, $\Delta \mathrm{G}^{\mathrm{o}}$ is standard free energy.

\begin{tabular}{|c|c|c|c|}
\hline \multicolumn{4}{|c|}{$\begin{array}{c}\text { TABLE-3 } \\
\text { THERMODYNAMIC PARAMETERS FOR } \\
\text { THE ADSORPTION OF Se(IV) ON NANO-TiO } \\
\end{array}$} \\
\hline $\mathrm{T}(\mathrm{K})$ & 273 & 293 & 313 \\
\hline $\mathrm{K}_{\mathrm{c}}$ & 19.00 & 17.37 & 14.53 \\
\hline$\Delta \mathrm{G}^{\mathrm{o}}\left(\mathrm{kJ} \mathrm{mol}^{-1}\right)$ & -3.54 & -3.94 & -4.94 \\
\hline$\Delta \mathrm{H}^{\mathrm{o}}\left(\mathrm{kJ} \mathrm{mol}^{-1}\right)$ & - & 22.03 & - \\
\hline$\Delta \mathrm{S}^{\mathrm{o}}\left(\mathrm{kJ} \mathrm{mol}^{-1} \mathrm{~K}^{-1}\right)$ & 0.09366 & 0.08863 & 0.08617 \\
\hline
\end{tabular}
Table-3 represents the estimated thermodynamic parameters for $\mathrm{Se}(\mathrm{IV})$ adsorption.

It can be seen from Table- 3 that positive $\Delta \mathrm{H}^{\mathrm{o}}$ indicates that the adsorption reaction of $\mathrm{Se}(\mathrm{IV})$ on nano- $\mathrm{TiO}_{2}$ is endothermic. The free energy value for all the systems are negative and decrease in the value of $\Delta \mathrm{G}^{\circ}$ with increase of temperature shows that the reaction is easier at high temperature. Metal ions in aqueous media are hydrated. When the ions get absorbed on the sorbent surface, water molecules previously bonded to the metal ion get released and dispersed in the solution; the results in an increase in the entropy ${ }^{21}$.

\section{Conclusion}

The experimental results indicate that nano- $\mathrm{TiO}_{2}$ is an effective sorbent for the adsorption of $\mathrm{Se}(\mathrm{IV})$ from aqueous solutions. The percentage of Se(IV) removal from solution by nano- $\mathrm{TiO}_{2}$ is $93 \%$ at $\mathrm{pH} 11.0$. For all studied systems of kinetics, the pseudo-second-order model provides better correlation of the adsorption data than the pseudo-first-order model. The adsorption isotherms could be well fitted by the Langmuir adsorption isotherm equation. The thermodynamic parameters $\Delta \mathrm{G}^{\mathrm{o}}, \Delta \mathrm{H}^{\mathrm{o}}$ and $\Delta \mathrm{S}^{\mathrm{o}}$ are calculated and the positive values of enthalpy confirm the endothermic nature of adsorption.

\section{ACKNOWLEDGEMENTS}

The authors acknowledged the Ankang University Special Foundation of High-level Personnel (No. AYQDZR200933) for financial support. 'The authors also thank our colleagues and other students who participated in this work.

\section{REFERENCES}

1. D. Peak, U.K. Saha and P.M. Huang, Soil Sci. Soc. Am. J., 70, 192 (2006).

2. N. Zhang, L.S. Lin and D.C. Gang, Water Res., 42, 3809 (2008).

3. D.G. Barceloux, J. Toxicol. Clin. Toxicol., 37, 145 (1999).

4. C. Breen, Appl. Clay Sci., 15, 187 (1999).

5. V. Mavrov, S. Stamenov, E. Todorova, H. Chmiel and T. Erwe, Desalination, 201, 290 (2006).

6. D. Prats, M.F. Chillon-Arias and M. Rodriguez-Pastor, Desalination, 128, 269 (2000).

7. T. Catal, H. Bermek and H. Liu, Biotechnol. Lett., 31, 1211 (2009).

8. N. Yee, J. Ma, A. Dalia, T. Boonfueng and D.Y. Kobayashi, Appl. Environ. Microbiol., 73, 1914 (2007).

9. M. Kashiwa, S. Nishimoto, K. Takahashi, M. Ike and M. Fujita, J. Biosci. Bioeng., 89, 528 (2000).

10. M. Morita, H. Uemoto and A. Watanabe, Eng. Life Sci., 7, 235 (2007).

11. T. Nishimura, H. Hashimoto and M. Nakayama, Sep. Sci. Technol., 42, 3155 (2007).

12. M.E. Claesson and A.P. Philipse, Colloids Surf. A, 297, 46 (2007).

13. L. Zhang, T. Huang, X.Y. Liu, M. Zhang and K. Li, J. Anal. Chem., 66, 368 (2011).

14. L. Zhang, T. Huang, M. Zhang, X.J. Guo and Z. Yuan, J. Hazard. Mater., 156, 352 (2008).

15. L. Zhang, T. Huang, N. Liu, X.Y. Liu and H.M. Li, Microchim. Acta, 165, 73 (2009).

16. S. Lagergren, Kungliga Svenska Vetenskapsakademiens, Handlinger, 24, 1 (1898).

17. Y.S. Ho and G. McKay, Trans. IchemE, 76(B), 332 (1998).

18. J.A. Kilner and B.C.H. Steele, Non-stoichimetric Oxides, Academic Press, New York, p. 233 (1981).

19. C.P Huang and W.P. Cheng, J. Colloid Interf. Sci., 188, 270 (1997).

20. G. Bereket, A.Z. Aroguz and M.Z. Ozel, J. Colloid Interf. Sci., 187, 338 (1997).

21. K. Ayben and B. Binay, J. Appl. Radiat. Isotopes, 58, 155 (2003). 